\title{
Physical Properties of Banana Stem and Leaf Papers Laminated with Banana Film
}

\section{Natcharee JIRUKKAKUL}

Faculty of Applied Science and Engineering, Nongkhai Campus, Khon Kaen University, Nong Khai 43000, Thailand

(Corresponding author's e-mail: pnatch@kku.ac.th)

Received: 19 January 2017, Revised: 23 February 2018, Accepted: 4 March 2018

\begin{abstract}
A sustainable development requires the use of bio-based packaging materials because of ready availability and limited environment impact. The porous structure and hydrophilic nature of cellulose in paper based materials needs to be combined or laminated with other materials to overcome these limitations. The fiber found in the banana stems and leaves, it is possible to use these raw materials in pulp processing and banana flour can be produced into an edible film. The aim of the study was to discover a suitable method (wet lamination or dry lamination) for producing paper (stems, leaves, or a 1:1 ratio of mixed stems and leaves) lamination with banana film and to study their physical properties for packaging application. Banana flour (4\%) solution was used as adhesive media between paper and film for wet lamination process where as the heating and compression were applied for dry lamination process. The results showed the efficiency of banana stems for paper production. However, there was an improvement in results when a 1:1 ratio of mixed stems and leaves was used due to an increase in tensile strength, elongation, and the $\mathrm{L}$ value. There was no significance in the water vapor permeability in all treatments. All treatments of paper lamination expressed $6-13 \%$ moisture content. The separation of film and paper layers occurred in dry lamination samples. The wet lamination of the leaf paper and mixed paper caused high tensile strength and elongation. Therefore, it could be used as an alternative and environmentally friendly method in the application of packaging materials.
\end{abstract}

Keywords: Banana leaf, banana stem, paper, banana film, physical properties

\section{Introduction}

The growing population with its increasingly urban life style, has inevitably had an impact on the comfortable packaging. Plastics were selected because of their physical and functional properties. Including, various surface modifications of paper such as the application of waxed and multilayered lamination with polyethylene, polyvinyl chloride, ethylene vinyl alcohol copolymer and aluminum films are used in the markets, they improve good strength, transparent and high temperature used but they present environmental problems related to material recycling and recovery process [1]. Consequently, the development of edible or biodegradable packaging from natural materials has increasingly attracted attention. Natural biodegradable polymers can potentially serve as environmentally friendly packaging or coating materials [2].

Paper is an excellent material for various applications because of its biodegradability, light weight, good mechanical properties and recyclability but its porous and fibrous network structure, poor barrier properties affected to the packaging applications [3]. Traditionally, paper is made from wood which is dependent on forest resources. Millions of trees are fallen daily since the use of forest sourced fiber has considerably increased recently. Moreover, environmental considerations have increased the necessary 
http://wjst.wu.ac.th

for using non-wood pulp as a low cost raw material for paper making [4]. Sources mulberry, pineapple leave, banana fiber and rice straw have previously been possibility for paper making [1,4-6].

Bananas are grown in humid tropical countries and are ranked as the world's fourth largest fruit crop after grapes, citrus fruits, and apples. More than 100 countries produce bananas [7]. Banana flesh has high flour which can serve as the ingredient for film production. Moreover, their leaf and stem which was considered an agricultural waste, could be used to produce paper [8]. Especially, banana stem contain high cellulose fiber which is major ingredient of paper production [9]. Banana fiber which was extracted from banana by-product of banana cultivar contain $50 \%$ cellulose and $17 \%$ lignin [10], could be replaced the synthesis polymer to enhance impact performance and improve mechanical properties [11].

In the process of creating edible films made from bananas, it is required to initially heat them to the gelatinization temperature, and then to subsequently cool them into films [12]. Depending upon the type and components of the flour, the properties of the films differ. The properties can be improved by adding food additives, such as plasticizers or oils that can affect the intermolecular bonding and can lead to greater flexibility [13]. Moreover, banana film made from banana starch, has been found to have a high tensile strength value [14]. Banana film has a special property that allows it to be sealed with a heat sealing machine $[15,16]$. Therefore, this makes it possible to coat or laminate paper, which offers advantages, such as water barrier increase, mechanical properties improvement, low costs and the ability to add colors and flavors to it which can make it more attractive for the consumer [17]. Moreover, this material can help to reduce plastic waste from food packaging and can allow for the creation of new products.

The aim of the study was to determine the lamination process of banana film on banana paper and to evaluate the physical properties of the paper obtained. This was accomplished by examining the water vapor permeability, tensile properties, moisture content, and the color, as well as conducting an examination of the paper with a scanning electron microscope.

\section{Materials and methods}

\section{Film preparation}

Raw bananas of the Musa ABB group at the maturity green stage were obtained from a local market at Nong Khai, Thailand. All mature green bananas had green peel color [16]. Banana flour solution was prepared by immersing bananas in boiling water for $5 \mathrm{~min}$, peeling off the skin, and then slicing them into small pieces. The pieces were dried at $60{ }^{\circ} \mathrm{C}$ for $8 \mathrm{~h}$ in hot air oven before they were ground using the hammer mill and sieved through 80 mesh. The banana flour was thus obtained [18]. A $4 \%$ banana flour solution was heated to $85{ }^{\circ} \mathrm{C}$ for $20 \mathrm{~min}$ on hot plates and was stirred. Glycerol $(1 \% \mathrm{w} / \mathrm{w})$ was added to the banana flour solutions. The solution was stirred by mechanical stirring. The final solution was poured into plates $(50 \mathrm{ml})$ and dried at $55^{\circ} \mathrm{C}$ for $24 \mathrm{~h}$ in hot air oven. The film was peeled off at ambient temperature and was kept in a desiccator before it was examined further. The thickness of film was $0.18 \pm 0.1 \mathrm{~mm}$ in the average.

\section{Paper prepapration}

Banana stems and leaves from mature banana plants of the Musa ABB group were collected from a field in Nong Khai, Thailand. The sun dried materials were milled in a spinner machine and sieved through 60 mesh. The fraction was extracted with $10 \% \mathrm{NaOH}$ for $2 \mathrm{~h}$ and was then rinsed in a porous plate. The pulp was washed with water until the alkalinity was lost. Both the pulp and the plate were dried in hot air oven for $8 \mathrm{~h}$. The paper from the stems and the paper from the leaves were obtained [9]. The thickness of paper was $0.53 \pm 0.07 \mathrm{~mm}$ in the average.

\section{Lamination process}

In order to compare the effectiveness of the lamination, both wet and dry laminating methods were used in experiment. In the wet lamination, the $4 \%$ banana flour solution was applied as adhesive between the film and the paper by brushing on the paper surface then placed the banana film on the paper. The laminated paper was overlay with smooth and heavy material for $1 \mathrm{~h}$ in the room temperature. Then the 
http://wjst.wu.ac.th

solvent was removed from the laminated paper by using a hot air oven for $5 \mathrm{~h}$. In the other method of dry lamination, the film adheres to the paper because the film, which is mainly composed of starch, behaves as the adhesive. The banana film was placed on the paper then heat and press were applied on the laminated paper with iron in the medium scale for $1 \mathrm{~min}$. As a result, the film and the paper are bonded by the high temperature and the compression force. The wet laminated paper was smoother than dry laminated paper and tend to stick together. The thickness of wet and dry laminated papers were $0.66 \pm 0.09$ $\mathrm{mm}$ and $0.72 \pm 0.12 \mathrm{~mm}$, respectively. Before the laminated papers were tested, they were kept in a dessicator. The experiment was the $3 \times 2$ factorials design. Two treatments were used on the paper materials (stems, leaves, and mixture of stems \& leaves at a 1:1 ratio) and the methods of coating were wet lamination and dry lamination.

\section{Water Vapor Permeability (WVP)}

The barrier properties are essential for the packaging. WVP is measured as the amount of water that permeates through the material of fixed thickness per unit time and area at a particular level of permanent gradient according to the standard method [19]. WVP tests of papers and laminated papers were performed using the gravimetric modified cup method based on ASTM E96 [20]. The test cups were filled with $30 \mathrm{ml}$ distilled water to achieve $100 \%$ relative humidity on one side of the paper. The paper was placed on the cup and was sealed with a sealant ring. Paper with the exposed area of $18.87 \mathrm{~cm}^{2}$ were tested. Silica gel was then used to control the relative humidity on the other side of paper. The average temperature and relative humidity were measured at $30 \pm 1{ }^{\circ} \mathrm{C}$ and $65 \pm 5 \%$ (Temperature and humidity meter, AMTEST, TH90: accuracy $\pm 1{ }^{\circ} \mathrm{C}$ and $\left.\pm 5 \% \mathrm{RH}\right)$. The temperature and relative humidity were recorded though the experiment and the mean value was calculated. The sample cups were weighed every $1 \mathrm{~h}$ until a constant weight was achieved. An accurate weight loss (g) versus time (h) was plotted to obtain a straight line and then the slope was measured. The WVP was calculated by using the following equation;

$$
W V P=\frac{\text { slope } \times x}{A \times \Delta p}
$$

where the slope is the gradient of the plot of weight loss versus time (g/day), $\mathrm{A}$ is the paper surface area $\left(\mathrm{m}^{2}\right), x$ is the paper thickness $(\mathrm{mm})$, and $\Delta p$ is the vapor pressure difference between the inside and the outside of the cell $(\mathrm{kPa})$.

\section{Tensile properties}

Tensile strength (TS) and elongation (E) are very important for packaging materials due to the handing and shipping of products. TS and E of the samples were determined using Texture analyzer (Micro Stable Systems, Godalming, UK). The test was perform in accordance with ASTM D882 [21]. Papers and laminated papers were prepared in $1 \times 15 \mathrm{~cm}^{2}$ and the initial gauge separation and crosshead speed were fixed at $10 \mathrm{~mm}$ and $50 \mathrm{~mm} / \mathrm{min}$, respectively. The samples were analysed in the standard atmosphere at $25{ }^{\circ} \mathrm{C}$ of temperature and $50 \%$ of relative humidity. During the sample stretching, several load and elongation data were recorded until the break of a sample occurred [19]. The tensile strength was calculated from the maximum force by dividing it by the area of cross section. The elongation at breaking was calculated from the ratio of the increase in length and was expressed in percentages.

\section{Moisture content (MC)}

The moisture content of the paper was determined following AOAC [22]. Initially, the paper was weighed and was placed in hot air oven at $105^{\circ} \mathrm{C}$ for $24 \mathrm{~h}$ and then was weighed again. The loss of water was calculated by the moisture content in the paper. 
http://wjst.wu.ac.th

\section{Color}

The color is not one of the main properties for packaging material but it is important for future finishing and printing procedure which described by hue, saturation and lightness. Generally, packaging paper made from kraft paper which is unnecessary to bleaching so it is low cost for production but the papers for writing and printing are bleaching with oxygen, ozone or hydrogen peroxide because it effects on their application [23]. Kraft paper is paper with high elasticity and tear resistance used for products which require good strength and durability such food packaging but it is brown color [19]. The color of the paper was measured with the Hunter Lab Spectrocolorimeter (Color meter, JS555, China). The sample was put into the test cell and covered. The color was measured by the CIELab system and reported the $\mathrm{L}^{*}, \mathrm{a}^{*}$, and $\mathrm{b}^{*}$ values of the samples.

\section{Scanning electron microscope}

The surface and cross-sectional morphology of the paper were examined using a scanning electron microscopy (SEM) [24]. Samples were coated with gold under a vacuum. SEM was carried out to give further insight on the coatings. The examination was completed using an accelerating voltage of $20 \mathrm{kV}$. The magnifications were $100 \times$ and $200 \times$ for surface and cross section, respectively.

\section{Statistics}

Excel and SPSS software were utilized when analyzing the data. Analysis of variance (ANOVA) and Duncan's Multiple Range Test (DMRT) were used to determine the significant differences between the means. The level of significance was $95 \%$.

\section{Results and discussion}

\section{Water vapor permeability}

WVP are important for packaging materials that estimate and predict the product shelf-life. The paper which is hydrophilic nature and porous structure, has high WVP and it is not good materials for packaging [2]. In the same way, edible films contain hydrophilic components such as polysaccharide caused higher WVP than the hydrophobic components such as lipid [25]. WVP of the laminated paper (11 - 16 g.mm $/ \mathrm{m}^{2}$.day.kPa) was not significantly different $(\mathrm{p}>0.05)$ from paper before laminated $(10-14$ g. $\mathrm{mm} / \mathrm{m}^{2}$.day.kPa). Similar results of WVP were observed for the paper laminated with chitosancaseinate film (7-14 g.mm $/ \mathrm{m}^{2}$.day.kPa) which decreased in WVP with increasing the concentration of caseinate [24]. The WVP values of banana film (polysaccharide), gelatin film (protein), candelilla wax (lipid), low density polyethylene and high density polyethylene (synthesis) were 2.04, 0.29, 0.015, 0.079 and $0.02 \mathrm{~g} . \mathrm{mm} / \mathrm{m}^{2}$.day.kPa, respectively $[18,26,27]$. The banana paper and laminated banana paper represented an alternative way to applied on fresh food which needed the air for respiration because the polysaccharide film are generally rather poor water barriers due to their hydrophilic nature. The addition of lipids to polysaccharide films affected good barriers to water vapor because lipid films have extremely low WVP because of their hydrophobic nature [27]. The low WVP laminated paper could be applied to the minimal required barrier for packaging materials were the humidity impact on foodstuff is a critical factor [2]. The WVP of the leaf paper was higher than the stem paper and the mixed paper (Figure 1) because leaf paper had a higher number of pores or spaces than the stem paper and the mixed paper which caused the vapor to permeate easily [28]. In process of mold up in to sheet form, the distribution of pulp before drying caused the pores which was high in the leaf paper because of low density. 


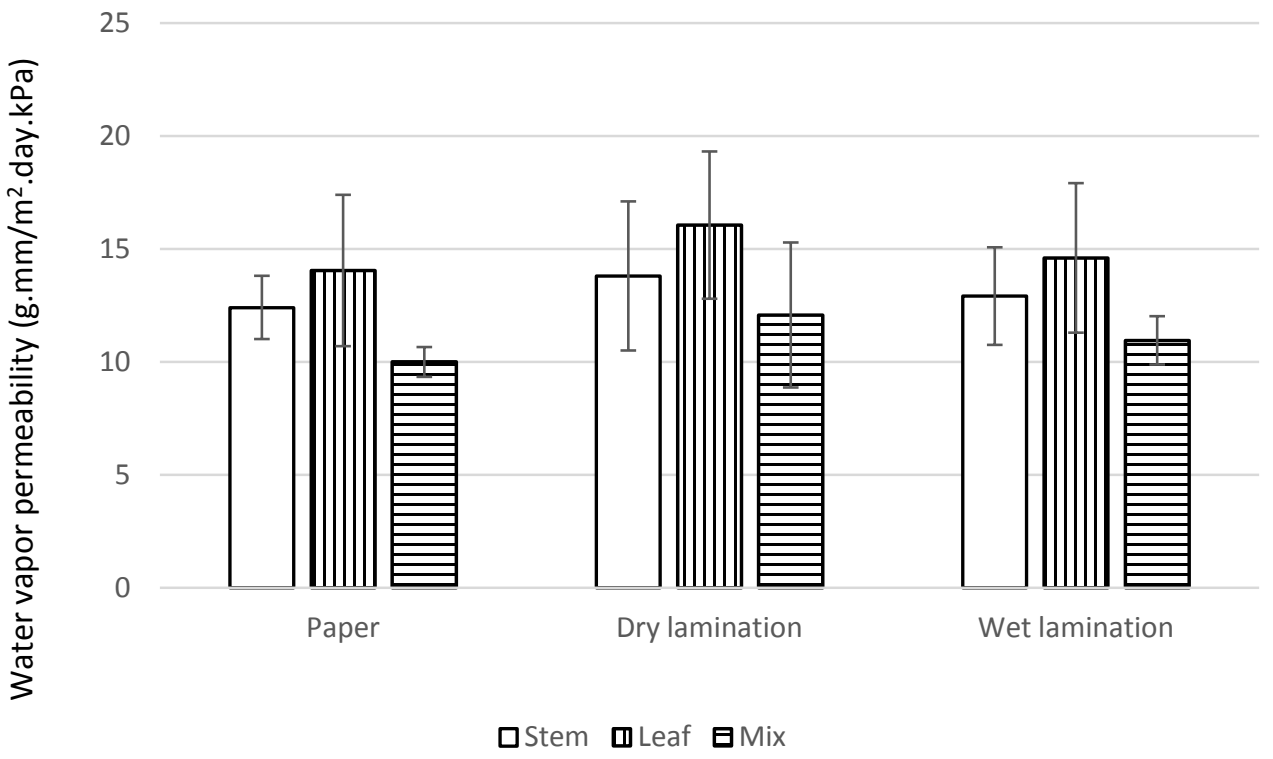

Figure 1 Water vapor permeability of paper with and without lamination.

\section{Tensile properties}

The stickiness of banana fiber caused the stem paper to have a higher TS than the leaf and the mixed paper [11]. The coating increased the strength of paper. Both the wet and the dry laminations had higher TS than the paper without lamination. The TS increased following weight of coating materials to all kinds of paper [24]. The moisture content has a great effect on the mechanical properties of paper. The nature of paper fracture depends on the bonding in the sheet which leads to short fiber. Thus, the lamination can be improved the TS [19]. The results showed that the wet lamination of the stem and the mixed paper had a higher TS than wet lamination of leaf paper (Figure 2) because the higher lignin contents (24.3\%) in leaf reduced mechanical properties of paper. Moreover, the high cellulose content of stem improved the embedding of single cellulose fiber in to polymer matrix which affected high TS [29]. The banana flour solution as the glue will interact intensively by improved mechanical strength of the wet lamination [2]. The mechanical properties of paper depend on inter-fiber bonding and so it is most probable that banana flour solution exerts its beneficial effects on paper by increasing the inter-fiber bond strength [30]. As a result, the TS of wet laminated paper was improved.

The TS was nearly the same as areca nut paper (3.24 MPa) [31]. The lamination affected higher TS than paper without lamination [32]. In the dry lamination, a separation between the film and the paper occurred which resulted in a tearing of the paper, but film still was extended. The dry laminated paper had higher elongation than the paper that had been wet laminated and the paper that had not been laminated. In previous research, paper laminated with polysaccharide film caused a high elongation of the film because the polysaccharides increased extension in the paper's structure [24]. 


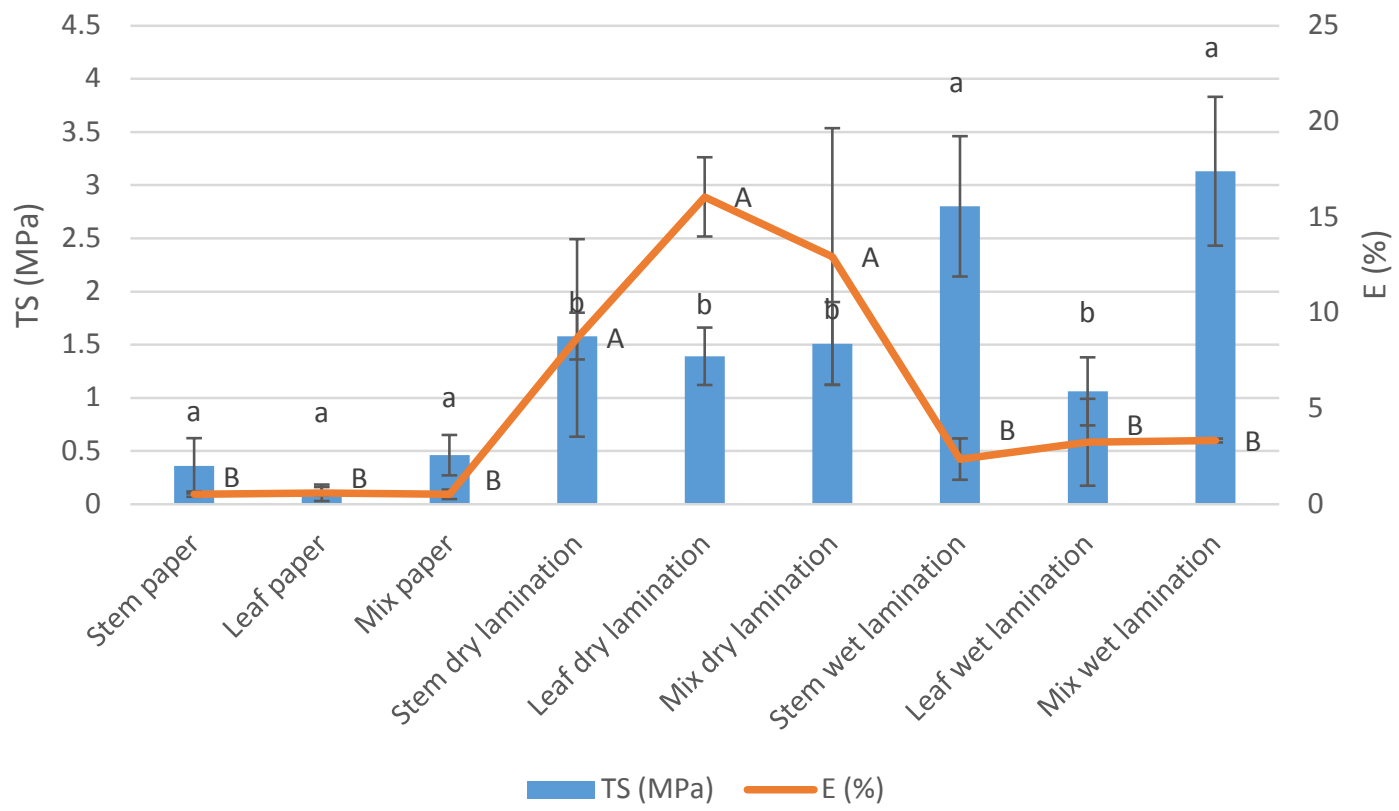

Figure 2 Tensile strength and elongation of paper with and without lamination.

Different small letters indicates the significant difference $(p<0.05)$ of tensile strength.

Different capital letters indicates the significant difference $(p<0.05)$ of elongation.

\section{Moisture content}

Because of its thickness and the lamination methods, the paper without lamination had a lower MC than the laminated paper (Figure 3). However, the papers and dry laminated papers that were obtained, MC had less than $9 \%$, so they were dry products. The wet laminated paper had higher MC (12.29 - 12.80 $\%)$ than the dry laminated paper and standard limit $(<10 \%)$ [33] because the flour solution which was applied as the adhesive material to adhere paper and film, increased MC of laminated paper. The conditions of the production process and storage were important with respect to changes in the MC. High levels of MC or high relative humidity storage condition have led to the growth of mold (MC $>14 \%$ ) [34]. High MC paper could be reduced by drying to control the final MC of paper. However, high temperatures during the drying process resulted in paper of low quality exhibiting the appearance of a rough surface [35]. 


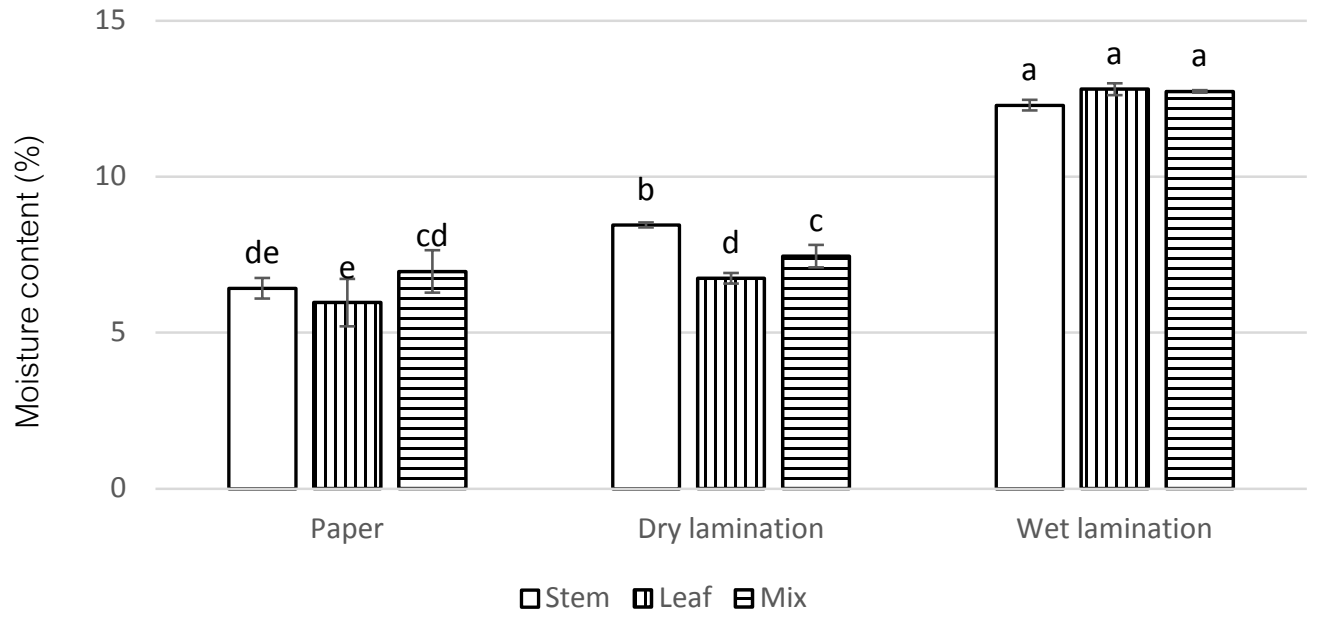

Figure 3 Moisture content of paper with and without lamination.

Different small letters indicates the significant difference $(\mathrm{p}<0.05)$.

\section{Color}

Color is important for future finishing and printing procedures indicating the quality of paper. The white papers are considered to high quality so bleaching process should apply on pulping industrial production. The laminated paper, that was obtained, had a transparent surface and light brown color. The $\mathrm{L}^{*}$ value was reduced, but because of the thickness of the paper, the $\mathrm{a}^{*}$ and the $\mathrm{b}^{*}$ values increased after lamination. The darkness of papers affected by the color of raw material including the yellowish of film which was applied on the paper, affected to the low $\mathrm{L}^{*}$ value [19]. Moreover, the heating to remove adhesive material in wet lamination process caused the lower $\mathrm{L}^{*}$ value than papers and dry laminated papers. The paper made from banana leaves had high $b^{*}$ value caused by the high $b^{*}$ value in the leaves because of material color (Table 1). However, the color is not of the main properties for packaging materials. Thus, the improvement of color paper should be conducted carefully in order not to influence any other properties.

Table 1 Color of paper with and without lamination.

\begin{tabular}{llll}
\hline Color & L & a & b \\
\hline Stem paper & $54.85 \pm 2.54^{\mathrm{a}}$ & $5.01 \pm 0.24^{\mathrm{c}}$ & $15.21 \pm 0.90^{\mathrm{c}}$ \\
Leaf paper & $50.50 \pm 1.20^{\mathrm{b}}$ & $8.98 \pm 0.77^{\mathrm{bc}}$ & $20.36 \pm 0.88^{\mathrm{b}}$ \\
Mixed paper & $56.27 \pm 1.73^{\mathrm{a}}$ & $6.82 \pm 0.42^{\mathrm{bc}}$ & $18.65 \pm 1.46^{\mathrm{bc}}$ \\
Stem dry lamination & $50.54 \pm 2.29^{\mathrm{b}}$ & $8.16 \pm 0.28^{\mathrm{bc}}$ & $18.10 \pm 1.69^{\mathrm{bc}}$ \\
Leaf dry lamination & $49.94 \pm 1.58^{\mathrm{b}}$ & $9.13 \pm 1.00^{\mathrm{bc}}$ & $18.24 \pm 1.94^{\mathrm{bc}}$ \\
Mixed dry lamination & $51.30 \pm 2.55^{\mathrm{ab}}$ & $9.07 \pm 0.25^{\mathrm{bc}}$ & $17.94 \pm 1.00^{\mathrm{bc}}$ \\
Stem wet lamination & $47.60 \pm 0.83^{\mathrm{c}}$ & $9.00 \pm 1.05^{\mathrm{bc}}$ & $19.87 \pm 1.83^{\mathrm{b}}$ \\
Leaf wet lamination & $44.03 \pm 2.39^{\mathrm{c}}$ & $12.23 \pm 2.17^{\mathrm{b}}$ & $25.50 \pm 5.00^{\mathrm{a}}$ \\
Mixed wet lamination & $43.82 \pm 2.21^{\mathrm{c}}$ & $18.72 \pm 12.59^{\mathrm{a}}$ & $20.86 \pm 3.26^{\mathrm{b}}$ \\
\hline
\end{tabular}

Different letters in the same column indicates the significant difference $(p<0.05)$. 
http://wjst.wu.ac.th

\section{Scanning electron microscope}

SEM expressed the structure of paper (Figure 4). The paper without lamination had clear fibers. The stem paper had higher density than leaf paper and mixed paper which had pores or spaces distributed among the fiber (Figures 4a - 4c). Leaf papers exhibit less pronounced orientation than stem papers with high amount of filler materials due to the expected short living nature of leave [28]. Regarding the TS, the results for the stem paper showed a higher value than the leaf paper. The wet laminated paper had smooth surface due to the film coating, (Figures $4 \mathbf{g}$ - 4i) because the adhesive material has been performed to improve the adhesion between the film and paper through hydrogen bonds, preventing the separation of the 2 layers when the laminates are handled [2]. Cracks were found in the dry laminated paper (Figures 4d - 4f). A cross-section of the laminated paper showed the laminated quality (Figure 5). In the wet laminated paper, it was found that there was a small space between layers of film and paper (Figures 5g 5i). By contrast, a large space was found in the dry laminated paper (Figures 5d - 5f) because there had been no adhesive media between film and paper. In the dry lamination method, heat was used to melt some parts of film for adhesion to the paper, so it could not spread along the sheet. The wet lamination method was suitable for producing the paper lamination.

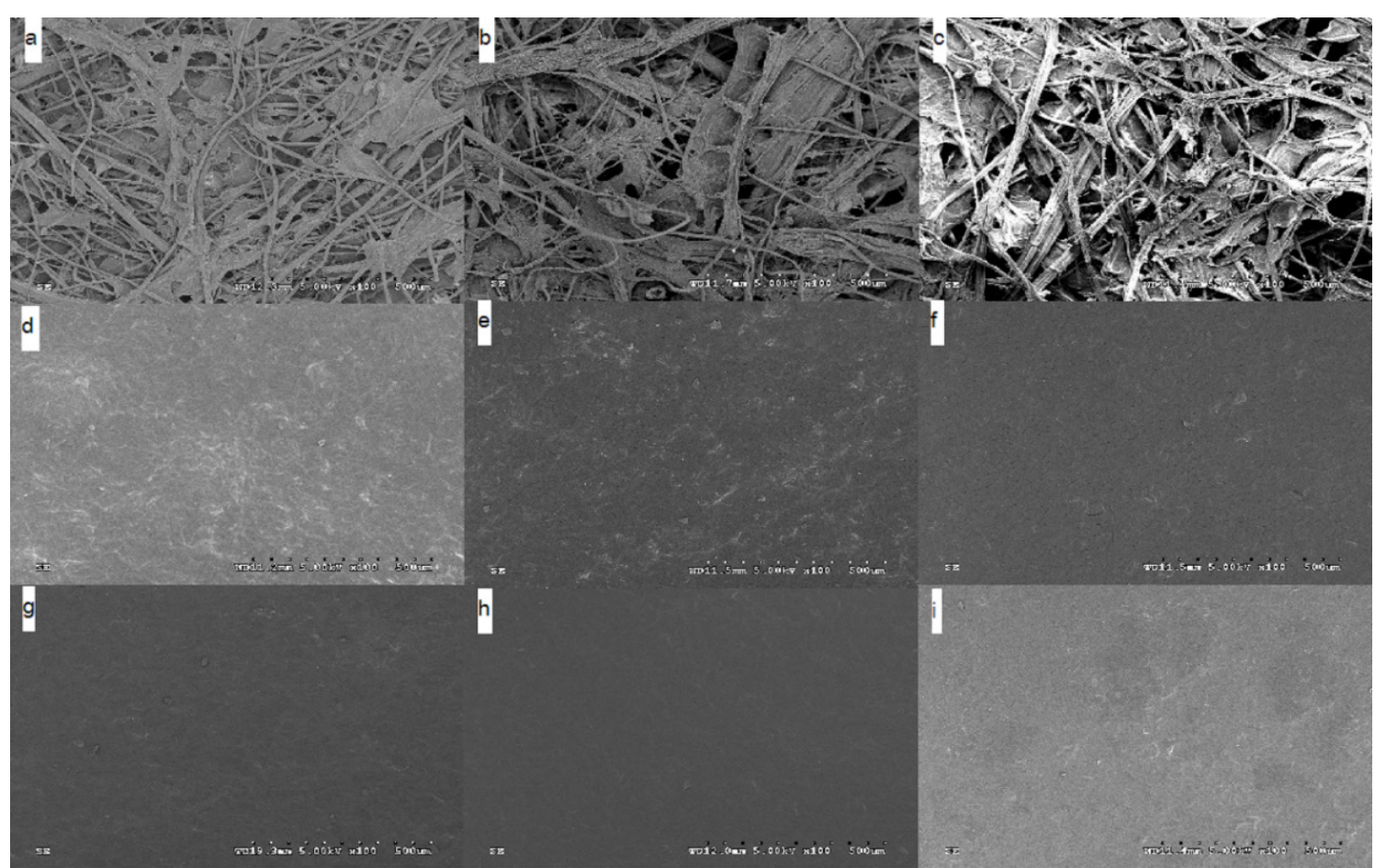

Figure 4 SEM image surface $(100 \times)$ of a) stem paper b) leaf paper c) mixed paper d) stem paper wet lamination e) leaf paper wet lamination $\mathrm{f}$ ) mixed paper wet lamination g) stem paper dry lamination $\mathrm{h}$ ) leaf paper dry lamination i) mixed paper dry lamination. 

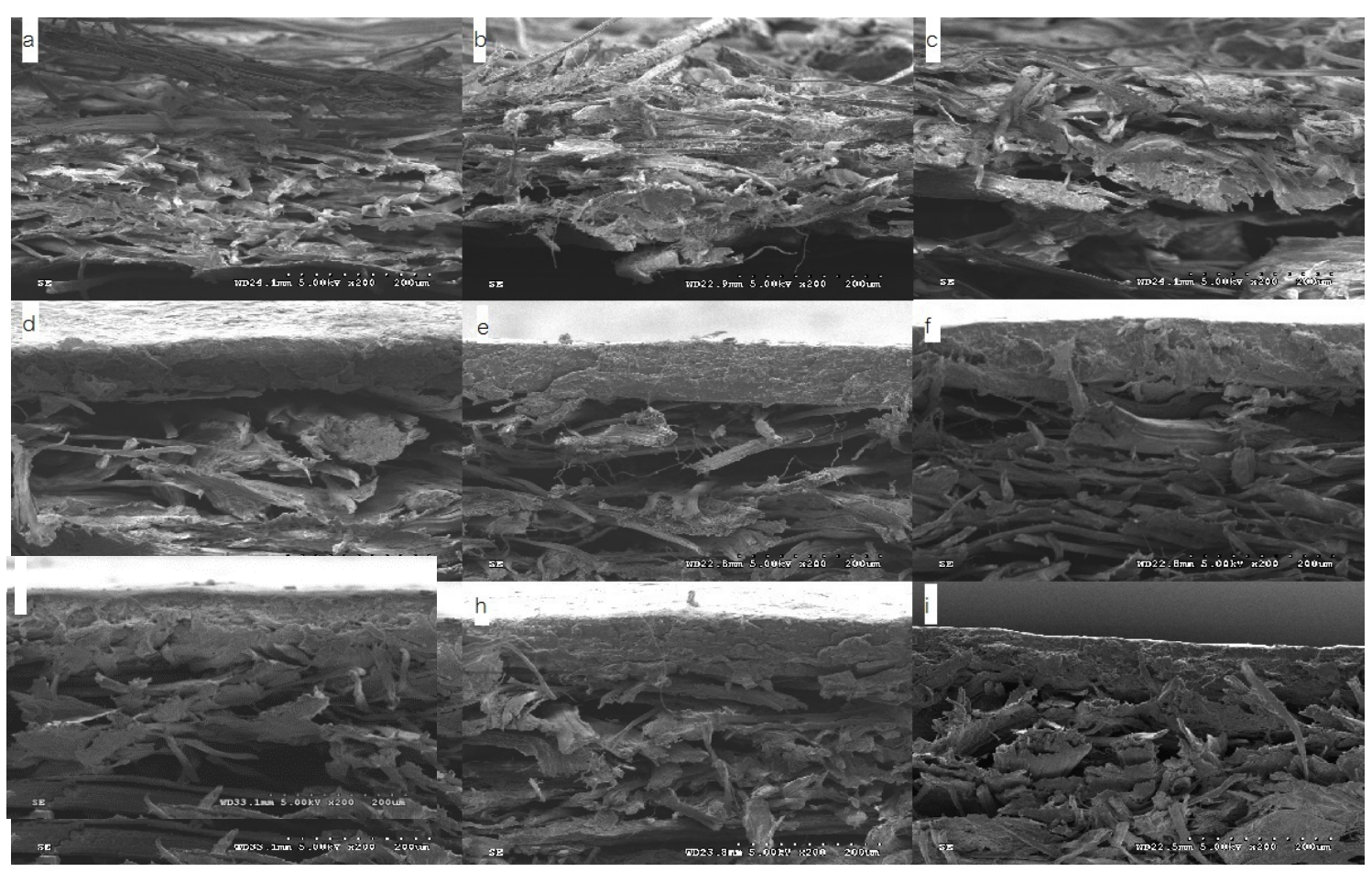

Figure 5 Cross-sectional SEM image (200×) of a) stem paper b) leaf paper c) mixed paper d) stem paper dry lamination e) leaf paper dry lamination f) mixed paper dry lamination g) stem paper wet lamination $\mathrm{h}$ ) leaf paper wet lamination i) mixed paper wet lamination.

\section{Conclusions}

The film lamination on paper did not have an effect upon the WVP, but caused a high TS, a high E, and a low lightness. The wet laminated paper had a smoother surface, a higher TS, and a greater degree of adhesion between the film and the paper. Therefore, the wet lamination method expressed good mechanical properties which could make further material packaging applications possible.

\section{Acknowledgements}

The authors would like to thank Division of Research Administration, Khon Kaen University for financial support. All facilities from the Faculty of Applied Science and Engineering were also acknowledged.

\section{References}

[1] A Memon, S Ithisoponakul, S Pramoonmak, M Lawsuriyaonta, D Leenoi and N Passadee. A development of laminating mulberry paper by biodegradable films. Energ. Proc. 2011; 9, 598-604.

[2] A Ramos, S Sousa, DV Evtuguin and JAF Gamelas. Functionalized xylans in the production of xylan-coated paper laminates. React. Funct. Polym. 2017; 117, 89-96.

[3] J Jung, GM Raghavendra, D Kim and J Seo. One-step synthesis of starch-silver nanoparticle solution and its application to antibacterial paper coating. Int. J. Biol. Macromol. 2018; 107, 228590.

[4] A Ramdhonee and P Jeetah. Production of wrappling paper from banana fibres. J. Environ. Chem. Eng. 2017; 5, 4298-306. 
http://wjst.wu.ac.th

[5] S Sibaly and P Jeetah. Production of paper from pineapple leaves. J. Environ. Chem. Eng. 2017; 5, 5978-86.

[6] D Kaur, NK Bhardwaj and RK Lohchab. Prospects of rice straw as a raw material for paper making. Waste Manag. 2017; 60, 127-39.

[7] LA Bello-Pérez, A De Francisco, E Agama-Acevedo, F Gutierrez-Meraz and JL García-Suarez. Morphological and molecular studies of banana starch. Food Sci. Tech. Int. 2005; 11, 367-72.

[8] L Oliveira, D Evtuguin, N Cordeiro and AJD Silvestre. Structural characterization of stalk lignin from banana plant. Ind. Crops Prod. 2009; 29, 86-95.

[9] LC Alarcon and VA Marzocchi. Evaluation for paper ability to pseudo stem of banana tree. Proc. Mater. Sci. 2015; 8, 814-23.

[10] N Reddy and Y Yang. Fiber from Banana Pseudo-Stems. In: N Reddy and Y Yang (eds). Innovative Biofibers from Renewable Resources. Springer, Berlin, Heidelberg, 2015, p. 25-7.

[11] H Liu, Q Wu and Q Zhang. Preparation and properties of banana fiber-reinforced composites based on high density polyethylene (HDPE)/Nylon-6 blends. Bioresour Tech. 2009; 100, 6088-97.

[12] FM Pelissari, MM Andrade-Mahecha, PJA Sobral and FC Menegalli. Comparative study on the properties of flour and starch films of plantain bananas (Musa paradisiaca). Food Hydrocoll. 2013; 30, 681-90.

[13] FM Pelissari, MM Andrade-Mahecha, PJA Sobral and FC Menegalli. Optimization of process conditions for the production of films based on the flour from plantain bananas (Musa paradisiaca). LWT Food Sci. Tech. 2013; 52, 1-11.

[14] CA Romero-Bastida, LA Bello-Perez, MA Garcia, MN Martino, J Solorza-Feria and NE Zaritzky. Physicochemical and microstructural characterization of films prepared by thermal and cold gelatinization from non-conventional sources of starches. Carbohydr. Polym. 2005; 60, 235-44.

[15] R Sothornvit and N Pitak. Oxygen permeability and mechanical properties of banana films. Food Res. Int. 2009; 40, 365-70.

[16] N Pitak and SK Rakshit. Physical and antimicrobial properties of banana flour/chitosan biodegradable and self sealing films used for preserving Fresh-cut vegetables. LWT Food Sci. Tech. $2011 ; 44,2310-5$.

[17] M Lacroix. Chapter 13 Mechanical and Permeability Properties of Edible Films and Coatings for Food and Pharmaceutical Applications. In: ME Embuscado and KC Huber (eds). Edible Films and Coatings for Food Applications. Springer Science+Business Media, LLC, 2009, p. 347-62.

[18] N Jirukkakul. The study of edible film production from unriped banana flour and riped banana puree. Int. Food Res. J. 2016; 23, 95-101.

[19] UV Brodnjak. Influence of ultrasonic treatment on properties of bio-based coated paper. Prog. Org. Coat. 2017; 103, 93-100.

[20] American Standard Testing Method (ASTM). Standard Test Method for Water Transmission of Material E96. In: ASTM International. West Conshohocken, PA, 2000.

[21] American Standard Testing Method (ASTM). Standard Test Method for Tensile Properties of Thin Plastic Sheeting D882. In: ASTM International. West Conshohocken, PA, 1997.

[22] Association of Official Agricultural Chemists (AOAC). Official Methods of Analysis of AOAC International. In: AOAC International. Gaithersburg, USA, 2000.

[23] SCA (Svenska Cellulosa Aktiebolaget). Papermaking, Available at: http://publicationpapers.sca.com, accessed December 2010.

[24] K Khwaldia, AH Basta, H Aloui and H El-Saied. Chitosan-caseinate bilayer coatings for paper packaging materials. Carbohydr. Polym. 2014; 99, 508-16.

[25] TH McHugh, R Avena-Bustillos and JM Krochta. Hypophilic edible films: Modified procedure for water vapor permeability and explanation of thickness effects. J. Food Sci. 1993; 58, 899-903.

[26] N Jirukkakul and J Sodtipinta. Effects of the tomato pomace oil extract on the physical and antioxidant properties of gelatin films. Int. J. Food Eng. 2017; 3, 1-5.

[27] $\mathrm{TH}$ McHugh and JM Krochta. Permeability Properties of Edible Films. In: JM Krochta, EA Baldwin and MO Nisperos-Carriedo (eds). Edible Coatings and Films to Improve Food Quality. Technomic Publishing, USA, 1994, p. 139-87. 
http://wjst.wu.ac.th

[28] R Sothornvit. Effect of hydroxypropyl methylcellulose and lipid on mechanical properties and water vapor permeability of coated paper. Food Res. Int. 2009; 42, 307-11.

[29] P Lu, H Xiao, W Zhang and G Gong. Reactive coating of soybean oil-based polymer on nanofibrillated cellulose film for water vapor barrier packaging. Carbohydr. Polym. 2014; 111, 5249.

[30] M Prambauer, C Paulik and C Burgstaller. Evaluation of the interfacial properties of polypropylene composite laminates, reinforced with paper sheets. Compos. Part A 2016; 88, 59-66.

[31] GM Raghavendra, J Jung, D Kim and J Seo. Effect of chitosan silver nanoparticle coating on functional properties Korean traditional paper. Prog. Org. Coat. 2017; 110, 16-23.

[32] R Raghupathy, R Viswanathan and CT Devadas. Quality of paper boards from arecanut leaf sheath. Bioresour. Tech. 2002; 82, 99-100.

[33] E Afra, S Mohammadnejad and A Saraeyan. Cellulose nanofibils as coating material and its effects on paper properties. Prog. Org. Coat. 2016; 101, 455-60.

[34] TIS 170-2559. Thai Industrial Standard Kraft Paper. Ministry of Industry, Thailand, 2016.

[35] J Choi, YJ Chung, DI Kang, KS Lee and J Lee. Effect of radiation on disinfection and mechanical properties of Korean traditional paper, Henji. Radiat. Phys. Chem. 2012; 81, 1051-4.

[36] MGA Vietra and SCS Rocha. Drying conditions influence on physical properties of recycled paper. Chem. Eng. Process. 2007; 46, 955-63. 